\title{
PROMOTING LEARNER ENGAGEMENT: MEASURING AND CHARACTERIZING LEARNER ENGAGEMENT USING A COLLABORATIVE ONLINE LEARNING TOOL
}

\author{
Andrew McDowell, David Cutting, Angela Allen, Neil Anderson, \& Matthew Collins \\ School of Electronics, Electrical Engineering and Computer Science, \\ Queens University Belfast (United Kingdom)
}

\begin{abstract}
Promoting learner engagement in large cohorts is a well-documented problem. One solution adopted in the lecture space is 'backchannel' software, which in its simplest form, provides an online chat facility that operates alongside lecture delivery. This provides an opportunity for learners to interact and ask questions without the fear of speaking out in front of a large group. Similarly, backchannel software can be used outside the lecture space to enhance engagement; however, this use has not been fully explored. Accordingly, the aim of this work is to evaluate the benefits of backchannel software to promote engagement inside and outside of the lecture space. This was achieved using the TodaysMeet backchannel service to collect 2,022 messages from 185 learners undertaking a second semester, first year programming module at Queens University Belfast. Subsequently, the findings support continued use of backchannels for promoting learner engagement inside and outside the lecture space.
\end{abstract}

Keywords: Backchannel, student engagement, TEL, blended learning.

\section{Introduction}

As education becomes more accessible across the globe, large learner cohorts are increasingly synonymous with teaching in higher education (Gibbs \& Jenkins, 2014). While the increased uptake of education around the world is undoubtedly positive, the size of the resulting cohorts and corresponding reductions in staff-student ratios poses a number of challenges, many of them centered on promoting and maintaining learner engagement. From an educator's perspective, key challenges include building an understanding of class diversity to meet individual learning needs, overcoming the inability to work with individual learners for a meaningful amount of time, and difficulty engaging individual learners with relevant teaching and learning activities (Fortes \& Tchantchane, 2010). The 'large class' problem is certainly not new, with numerous approaches to mitigate the reported issues having been investigated. Many of these are from the domain of Technology Enhanced Learning (TEL) and of particular interest to this work, is the use of 'backchannel' software as a method to facilitate communication between learners and teaching staff.

A backchannel may be described as a complementary interaction that takes place alongside another activity or event. In an educational context, these typically take the form of chatroom-like software that allows learners to communicate with each other and the teaching staff while other activities are taking place (Baron, Bestbier, Case, \& Colier-Reed, 2016). Accordingly, this promotes interaction between learners and lecturer, but importantly between learners who may not normally interact with each other outside the backchannel. This leads to an increased number of questions and comments from the class and promotes the development of a learning community (Bry, Gehlen-Baum, \& Pohl, 2011; Fortes \& Tchantchane, 2010; Yong-Su Pohl \& Gehlen-Baum, 2011).

Focusing on the use of a backchannel, these often operate throughout the duration of a specific activity such as a lecture, however, learning within a taught module extends beyond scheduled timetabled sessions. Subsequently, it may be postulated that the learning community supported by a backchannel has a role beyond scheduled contact sessions. Accordingly, this work will consider how backchannels may promote engagement inside and outside the traditional lecture space. 


\section{Methodology}

For this work, a cohort of 185 learners undertaking a second semester, first year computer programming module at Queen's University Belfast were offered the opportunity to anonymously use the online backchannel service TodaysMeet (TM), formerly available at www.TodaysMeet.com. Accordingly, the TM service operated throughout the semester inside and outside of scheduled contact sessions ( 3 x $1 \mathrm{Hr}$ Lectures, 1 x $2 \mathrm{Hr}$ Lab), including holiday periods such as Easter. At the conclusion of the module the TM service was closed, at which point the messages posed throughout the semester were exported to a Microsoft SQL Server database for analysis as described in Sections 3 and 4 below.

\section{Results}

During the data acquisition period, a total of 2,022 messages were posted to TM service, 1,677 $(83 \%)$ by students and $345(17 \%)$ by the module lecturer. As illustrated in Table 1, each message consisted of the message text, the timestamp of the message and the message author. It is important to note that author names were anonymously set by students on TM, accordingly, one student may post under several pseudonyms and likewise, many students may pose as the same pseudonym. For this reason it is impossible to state the exact number of students who directly interacted with the backchannel platform, however, in total 399 unique student pseudonyms were used.

Table 1. Sample of three messages posted to the TM backchannel.

\begin{tabular}{|l|l|l|}
\hline Message Text & Timestamp & Author \\
\hline So... you would use the Try and Catch functions, if you are uncertain of the result? & $13 / 02 / 201714: 23$ & Peter \\
\hline Can you use try and catch with user input & $13 / 02 / 201714: 24$ & Dm \\
\hline What does .getMessage() do? & $13 / 02 / 201714: 33$ & eb \\
\hline
\end{tabular}

In order to measure the engagement of students with the TM service inside and outside of scheduled contact sessions, the distribution of messages was evaluated from two different perspectives as illustrated in Figures 1 and 2. Specifically, Figure 1 shows the number of messages posted during each week of module delivery, including the Easter break, while Figure 2 shows the distribution of all messages across a 24-hour period.

Figure 1. Number of messages posted to TM grouped by week number.

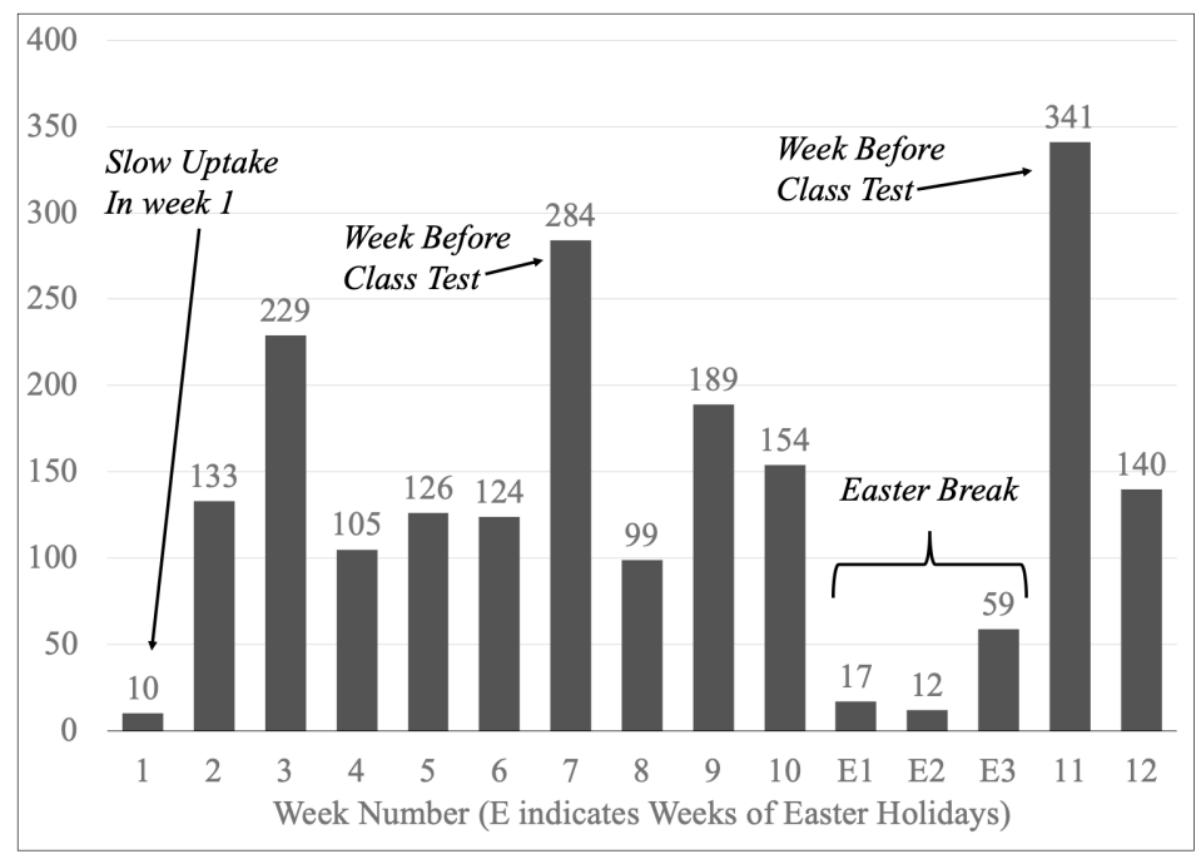


Figure 2. Number of messages posted to TM grouped by hour of day.

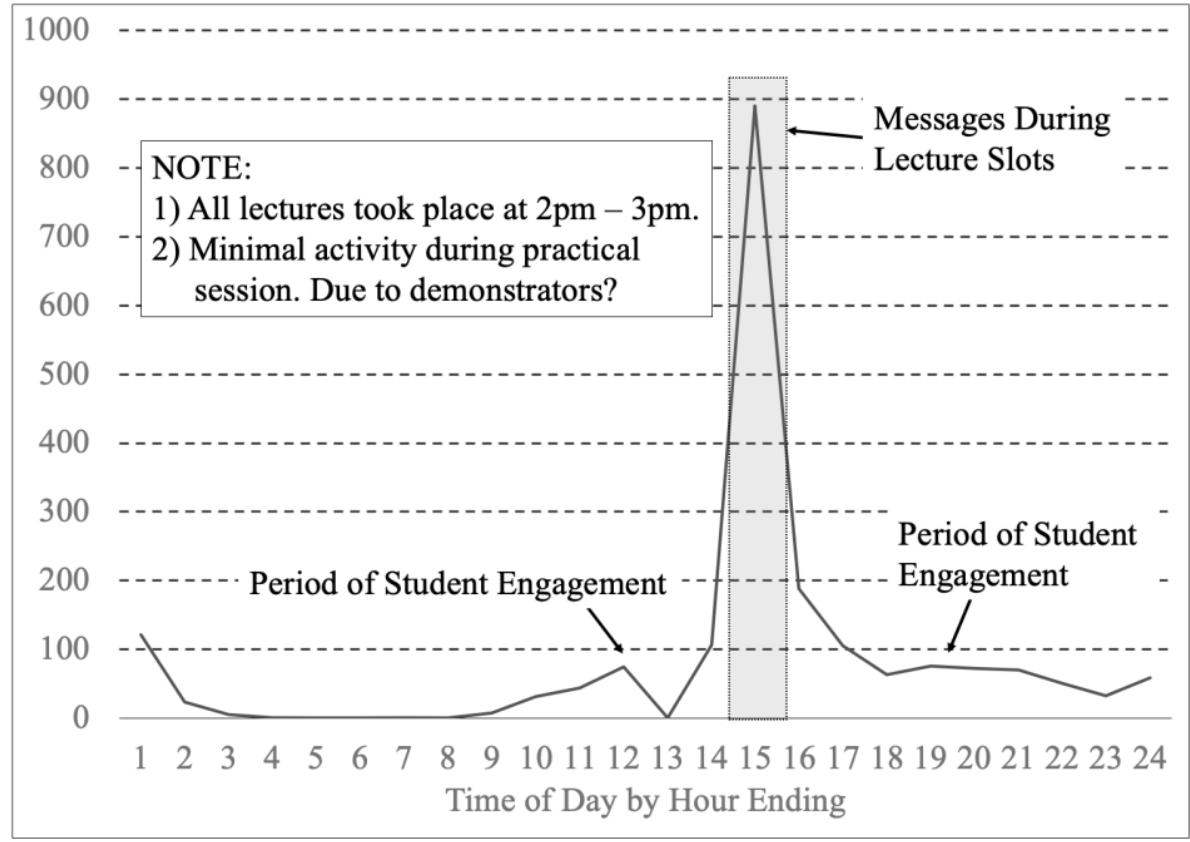

\section{Discussion}

Before considering the impact of backchannels on student engagement with this cohort, it is useful to outline the typical profile of student engagement prior to the introduction of TM. For cohorts such as the one described above, without TM, interaction in the lecture space was sparse with normally, no questions being posed during a session, despite attempts to encourage dialog from the lecturer. Conversely, at the end of a session, there was often a queue of students waiting to ask questions on the material covered, followed by a number of related email queries.

Following the introduction of TM, a significant increase in student interaction was observed as evidenced by the 1,677 messages posted by students. Some $890(53 \%)$ of these messages were posted during the lecture session indicating that more students were engaging with the material in real-time and getting answers to queries immediately, rather than having to wait until the end of the lecture. Correspondingly, there was a significant reduction in the number of student queries and emails at the end of each session. Considering the general profile of engagement throughout module delivery, Figure 1 shows that after an initial uptake period, students consistently engaged with TM. Interestingly, this includes 89 messages posted during the Easter period and a further 70 messages at weekends providing evidence that this backchannel tool promoted student interaction outside traditional contact hours. Overall, as illustrated in Figure 2, a total of 1,119 (55\%) messages were posted outside scheduled contact time indicating TM does promote engagement outside the lecture space. For example, evaluating message timings revealed that $401(20 \%)$ messages were posted in the hour preceding a lecture or in the two hours following. This may indicate that learners used TM to help prepare for and/or follow-up on lecture material. Similarly, another elevated period of activity is observable from $6 \mathrm{pm}$ into the evening.

In addition to measuring the quantity of activity on TM, the nature of how students interacted with the backchannel was of interest. For example, after acclimatizing to TM, it was also observed that learners began to answer each other's questions. This was highlighted by learners use of the '@' symbol 116 times to tag classmates when answering their queries. Moderation aside, this behaviour produced significant benefits including a reduced workload for the lecturer, the building of relationships between learners and the cultivation of a very positive collaborative learning environment. Furthermore, as illustrated in Figure 3, this opinion was seemingly shared by the student cohort based on their responses to the Teaching Evaluation Questionnaire issued to all students at the conclusion of each module. 
Figure 3. Sample of 12 student responses to the 'good practice' question of the Teaching Evaluation Questionnaire for the student cohort described in Section 2.

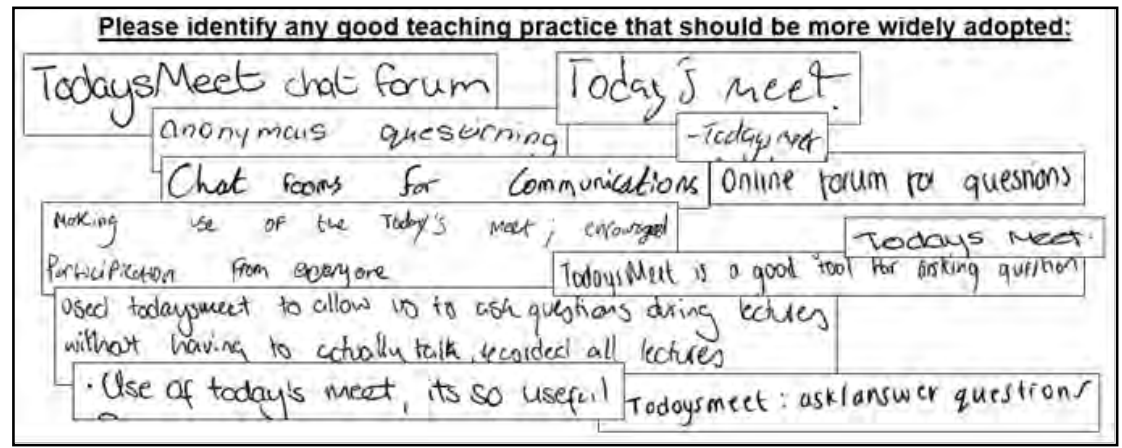

\section{Conclusion}

This paper aimed to explore the benefits of backchannel software to promote engagement inside and outside of the lecture space. Accordingly, based on this sample of one cohort as described in Section 2, three key observations have been made. (1) There has been a distinct increase in the volume of discussions and questions during lecture sessions. (2) Students were engaging with the backchannel service outside scheduled contact time, including weekend and holiday periods. (3) Student-student interactions along with the positive feedback received around the use of TM indicate that a learning community is being formed via the backchannel.

While the cursory nature of the analysis presented here along with the comparatively small sample size used must be acknowledged, there remains sufficient evidence to support the continued investigation of backchannel software for promoting communication and learner engagement both inside and outside the lecture space. To this end, future works will strive to increase the scope of the data available and focus on developing a better understanding of the ways students perceive and interact with backchannels to generate the greatest learning benefit.

\section{References}

Baron, D., Bestbier, A., Case, J., \& Colier-Reed, B. (2016). Investigating the effects of a backchannel on university classroom interactions: A mixed-method case study. Computers \& Education, 94, 61-76.

Bry, F., Gehlen-Baum, V., \& Pohl, A. (2011). Promoting awareness and participation in large class lectures: The digital backchannel backstage. IADIS International Conference Esociety, 27-34. Retrieved from http://pms.ifi.lmu.de

Fortes, P. C., \& Tchantchane, A. (2010). Dealing with Large Classes: A Real Challenge. $\begin{array}{llll}\text { Procedia - Social and Behavioral } & \text { Sciences, }\end{array}$ https://doi.org/10.1016/J.SBSPRO.2010.12.037

Gibbs, G., \& Jenkins, A. (2014). Teaching large classes in higher education: How to maintain quality with reduced resources. Routledge.

Yong-Su Pohl, A., \& Gehlen-Baum, V. (2011). Introducing Backstage - a digital backchannel for large class lectures. Interactive Technology and Smart Education, 8(3), 186-200. 